\title{
Birthweight of babies born to migrant mothers - What role do integration policies play?
}

Sørbye, Ingvil K; Vangen, Siri; Juarez, Sol P; Bolumar, Francisco; Morisaki, Naho; Gissler, Mika; Andersen, Anne-Marie N; Racape, Judith; Small, Rhonda; Wood, Rachael; Urquia, Marcelo L

Published in:

SSM - Population Health

DOI:

10.1016/j.ssmph.2019.100503

Publication date:

2019

Document version

Publisher's PDF, also known as Version of record

Document license:

CC BY-NC-ND

Citation for published version (APA):

Sørbye, I. K., Vangen, S., Juarez, S. P., Bolumar, F., Morisaki, N., Gissler, M., Andersen, A-M. N., Racape, J., Small, R., Wood, R., \& Urquia, M. L. (2019). Birthweight of babies born to migrant mothers - What role do integration policies play? SSM - Population Health, 9, [100503]. https://doi.org/10.1016/j.ssmph.2019.100503 
Article

\title{
Birthweight of babies born to migrant mothers - What role do integration policies play?
}

\author{
Ingvil K. Sørbye ${ }^{\mathrm{a}, *}$, Siri Vangen ${ }^{\mathrm{a}}$, Sol P. Juarez ${ }^{\mathrm{b}}$, Francisco Bolumar ${ }^{\mathrm{c}, \mathrm{d}}$, Naho Morisaki ${ }^{\mathrm{e}}$, \\ Mika Gissler ${ }^{\mathrm{f}, \mathrm{g}}$, Anne-Marie N. Andersen ${ }^{\mathrm{h}}$, Judith Racape ${ }^{\mathrm{i}}$, Rhonda Small ${ }^{\mathrm{j}, \mathrm{k}}$, Rachael Wood ${ }^{1}$, \\ Marcelo L. Urquia ${ }^{\mathrm{m}, \mathrm{n}}$
}

\footnotetext{
a Norwegian Advisory Unit for Women's Health, Department of Obstetrics, Oslo University Hospital, Norway

${ }^{\mathrm{b}}$ Department of Public Health Sciences, Stockholm University, Sweden

${ }^{c}$ Unit of Public Health, School of Medicine, University of Alcalá, Madrid, Spain

${ }^{\mathrm{d}}$ City University of New York School of Public Health, New York, United States

${ }^{\mathrm{e}}$ Department of Social Medicine, National Center for Child Health and Development, Japan

${ }^{\mathrm{f}}$ THL National Institute for Health and Welfare, Information Services Department, Helsinki, Finland

${ }^{g}$ Karolinska Institute, Department of Neurobiology, Care Sciences and Society, Stockholm, Sweden

${ }^{\mathrm{h}}$ Faculty of Health Sciences, University of Copenhagen, Denmark

${ }^{i}$ École de Santé Publique, Faculté de Médecine, Université Libre de Bruxelles, Belgium

${ }^{\mathrm{j}}$ Judith Lumley Centre, La Trobe University, Melbourne, Australia

${ }^{\mathrm{k}}$ Department of Women's and Children's Health, Karolinska Institute, Stockholm, Sweden

${ }^{1}$ NHS National Services Scotland, Information Services Division, Edinburgh, Scotland, UK

${ }^{\mathrm{m}}$ Manitoba Centre for Health Policy, Rady Faculty of Health Sciences, University of Manitoba, Winnipeg, Canada

${ }^{\mathrm{n}}$ Dalla Lana School of Public Health, Faculty of Medicine, University of Toronto, Ontario, Canada
}

\section{A R T I C L E I N F O}

\section{Keywords:}

Migration

Birthweight

Pregnancy

MIPEX

\begin{abstract}
A B S T R A C T
Birthweights of babies born to migrant women are generally lower than those of babies born to native-born women. Favourable integration policies may improve migrants' living conditions and contribute to higher birthweights. We aimed to explore associations between integration policies, captured by the Migrant Integration Policy Index (MIPEX), with offspring birthweight among migrants from various world regions. In this crosscountry study we pooled 31 million term birth records between 1998 and 2014 from ten high-income countries: Australia, Belgium, Canada, Denmark, Finland, Japan, Norway, Spain, Sweden and United Kingdom (Scotland). Birthweight differences in grams (g) were analysed with regression analysis for aggregate data and random effects models.

Proportion of births to migrant women varied from $2 \%$ in Japan to $28 \%$ in Australia. The MIPEX score was not associated with birthweight in most migrant groups, but was positively associated among native-born (mean birthweight difference associated with a 10-unit increase in MIPEX: 105 g; 95\% CI: 24, 186). Birthweight among migrants was highest in the Nordic countries and lowest in Japan and Belgium. Migrants from a given origin had heavier newborns in countries where the mean birthweight of native-born was higher and vice versa. Mean birthweight differences between migrants from the same origin and the native-born varied substantially across destinations (70 g-285 g).

Birthweight among migrants does not correlate with MIPEX scores. However, birthweight of migrant groups aligned better with that of the native-born in destination counties. Further studies may clarify which broader social policies support migrant women and have impacts on perinatal outcomes.
\end{abstract}

\footnotetext{
* Corresponding author. Norwegian Advisory Unit for Women's health, Department of Obstetrics, Oslo University Hospital, 0027, Oslo, Norway.

E-mail addresses: isorbye@ous-hf.no (I.K. Sørbye), sirvan@ous-hf.no (S. Vangen), sol.juarez@su.se (S.P. Juarez), Francisco.bolumar@uah.es (F. Bolumar),

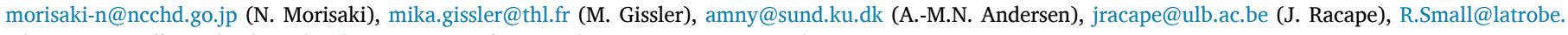
edu.au (R. Small), rachaelwood@nhs.net (R. Wood), marcelo_urquia@cpe.umanitoba.ca (M.L. Urquia).
} 


\section{Introduction}

Newborn size at term varies widely between and within countries (Urquia, Sørbye, \& Wanigaratne, 2016; Wilcox, 2001). At the population level, birthweight differences even within the "normal" range may reflect environmental disparities in health and living conditions (Weightman et al., 2012). Settings characterised by optimal maternal living conditions, fetal growth, and thus newborn size show only small variations across populations (Villar et al., 2014; Wehby, Gili, Pawluk, Castilla, \& Lopez-Camelo, 2015). However, in prospective studies of fetal growth curves substantial variation by maternal origin is found, even in low-risk populations (Gardosi, Francis, Turner, \& Williams, 2018). With conflicting data, how can we explore population birthweight differences further? Human migration creates a natural experiment in terms of a change in maternal living conditions. An increasing proportion of births in high-income countries are to migrant women (Indicators of Immig, 2015, pp. 37-51). Among migrants from low-resource countries living in a high-resource country, we find elevated rates of low birthweight and perinatal death in several groups (Gagnon, Zimbeck, \& Zeitlin, 2009; Gissler et al., 2009; Vangen et al., 2002). For example, South Asian women tend to give birth to smaller babies than non-migrant mothers (Ray et al., 2012; Seaton, Yadav, Field, Khunti, \& Manktelow, 2011). However, high-income countries differ in their efforts and success in integrating migrants. Integration is difficult to measure, although policies indicate the degree of effort made by a government to reduce obstacles to migrant participation and acceptance, something likely to affect health (Juarez et al., 2019). The Migrant Integration Policy Index (MIPEX) has been developed to capture policies and laws of EU and OECD countries that promote integration of migrants (Migrant Integration Polic, 2018). The MIPEX score covers eight policy areas: health, education, labour market mobility, family reunion, political participation, permanent residence, access to nationality and anti-discrimination. The index facilitates comparisons as to what governments are doing to promote integration, but has not been validated in terms of population health outcomes, such as birthweight.

Assuming no selection bias, if newborn birthweight varies depending on which high-income country migrant mothers from the same geographic origin move to, that may reflect potential differences in environmental factors in the destination countries. Poor living conditions, encompassing poor access to optimal maternity care, education and income-generating activities could contribute to smaller term babies. Stressors such as austerity measures or deportation raids have been associated with low birthweight among migrant groups (Kana, Correia, Peleteiro, Severo, \& Barros, 2017; Novak, Geronimus, \& Martinez-Cardoso, 2017) whereas beneficial integration policies have been linked to reduced risk of adverse birth outcomes (Bollini, Pampallona, Wanner, \& Kupelnick, 2009). Overall migrants in countries with exclusionist policies experience worse health compared to countries with multicultural policies (Malmusi, 2015).

On the other hand, native-born and migrant population groups share environmental influences. The risk of diabetes, obesity and maternal smoking in migrants has been shown to rise with increasing length of residence (Goel, McCarthy, Phillips, \& Wee, 2004; Hawkins, Lamb, Cole, \& Law, 2008; Oza-Frank, Stephenson, \& Narayan, 2011). Furthermore, migration is not a random event. Migration to particular countries often occurs based on shared language and historical attachments or particular admission criteria. Healthier and/or wealthier women may choose to migrate to richer countries where they can have better outcomes compared with those whose circumstances meant they only made it to less optimal destinations (Urquia, Vang, \& Bolumar, 2015).

Comparing birthweight among migrants in several destination countries is challenging, as the acquirement and sharing of multicountry data publicly across borders is increasingly difficult due to confidentiality concerns. Birthweight represents a suitable outcome to investigate variations among well-defined population subgroups across jurisdictions due to being measured with high accuracy and reliability across settings and for being sensitive to environmental influences (Wilcox, 2001). We restricted to term births due to variations in registration of births at the extremes of the gestational age distribution (Delnord et al., 2017; Joseph et al., 2012). For this study, we took advantage of the Reproductive Outcomes And Migration (ROAM) network (Reproductive Outcomes and, 2018) to access and pool cross-national birth and migration data. Our objective was twofold. First, we explored the association between integration policies in destination countries, as measured by the MIPEX score, and birthweight at term among migrants originating in the same world region. Assuming that MIPEX is an indicator of integration and higher scores are higher integration, we hypothesised that a higher MIPEX score would be associated with higher birthweights among migrants from the same geographic region, meaning that the distribution of BW at term would be shifted (boosted) to the right (Wilcox, 2001). Second, we explored how birthweight of migrants relates to the birthweight of the native-born population across destination countries.

\section{Materials and methods}

This was a cross-country comparative study. We used populationbased national and regional data from ten high-income OECD countries/regions. The study protocol was specified prior to data collection. Participating centres had to meet the following inclusion criteria: (a) categorisation of maternal region of origin according to pre-specified groups; (b) categorisation of data by maternal age, parity and year of birth within maternal regions of birth; (c) provision of the number of births and mean birthweight with standard deviation (SD) in each subgroup.

\subsection{Data sources and study population}

The study population included births from Australia (the state of Victoria), Belgium, Canada, Denmark, Finland, Japan, Norway, United Kingdom (Scotland), Spain and Sweden. Population health data were obtained from medical birth registries and perinatal data collections. Inclusion criteria were singleton livebirths and stillbirths between 37 and 41 completed gestational weeks among migrants and non-migrants occurring between 1998 and 2014. Pre- and post-term births $(<37+$ 0 or $\geq 42+0$ gestational weeks) and births with birthweight $<1000 \mathrm{~g}$ or $>6999$ were excluded. We used the best obstetric estimate for gestational age. Women could have contributed more than one birth to the cohort. Data from the most recent 10-12 year period were included with at least three years before 2008 and at least one year after 2008. Not all centres contributed data for all the years. Each participating centre assessed the internal consistency and quality of data, and obtained ethical approval to share the results. The study was approved by the Norwegian Regional Committee for Medical and Health Research Ethics, reference 2016/417.

\subsection{Outcome measures and predictors}

The main outcome was mean birthweight in grams $(\mathrm{g})$ with standard deviation reported in strata for the following categorical predictors: maternal region of birth, calendar year of birth, maternal age and parity. Information on maternal country of birth was used for classification into one of eight maternal regions of birth based on a modification of the United Nations sub-regions (Supplemental Table A) (United Nations Geographic, 2016): "Eastern Europe", "Rest of Europe", "Latin America/Caribbean", "North Africa/Middle East", "Sub-Saharan Africa", "South Asia", "Rest of Asia" and "North America/Oceania". For Japan, maternal region of origin could only be classified into four of the nine categories. Women born in the destination country ("native-born") were used as the reference category, where applicable. We reported data by each calendar year to account for time trends. Maternal age was categorised as $<35$ years or 35 years and above, and parity as 
Table 1

Births in destination country according to migrant status, maternal age, parity and year of birth.

\begin{tabular}{|c|c|c|c|c|c|c|c|c|c|c|}
\hline \multirow[t]{2}{*}{ Destination country } & \multirow[t]{2}{*}{ MIPEX $^{\mathrm{a}}$ score } & \multicolumn{2}{|l|}{ All births } & \multicolumn{2}{|l|}{ Migrants } & \multicolumn{2}{|l|}{ Native-born } & \multirow{2}{*}{$\frac{\text { Maternal age }<35}{\%}$} & \multirow{2}{*}{$\frac{\text { Para } 0}{\%}$} & \multirow{2}{*}{$\frac{\text { Year of birth }}{\text { Range }}$} \\
\hline & & $\mathrm{N}$ & $\%$ & $\mathrm{~N}$ & $\%$ & $\mathrm{~N}$ & $\%$ & & & \\
\hline Australia & 66 & 987742 & 3.1 & 275660 & 7.9 & 712082 & 2.6 & 76.7 & 42.6 & 1999-2014 \\
\hline Belgium & 68 & 1400792 & 4.5 & 372108 & 10.7 & 1028684 & 3.7 & 86.1 & 45.9 & 1998-2010 \\
\hline Canada & 71 & 4668940 & 14.9 & 1195375 & 34.3 & 3473565 & 12.4 & 82.9 & 43.9 & $1998-2012$ \\
\hline Denmark & 49 & 585542 & 1.9 & 82747 & 2.4 & 502795 & 1.8 & 82.7 & 41.4 & 1998-2010 \\
\hline Finland & 69 & 717066 & 2.3 & 48773 & 1.4 & 668293 & 2.4 & 81.2 & 40.5 & $2001-2014$ \\
\hline Japan & 42 & 14673357 & 46.7 & 288339 & 8.3 & 14385018 & 51.5 & 83.9 & 48.5 & 1998-2011 \\
\hline Norway & 70 & 842272 & 2.7 & 163558 & 4.7 & 678714 & 2.4 & 82.7 & 40.3 & 1998-2014 \\
\hline Scotland & 62 & 803077 & 2.6 & 83976 & 2.4 & 719101 & 2.6 & 81.5 & 44.8 & 1998-2014 \\
\hline Spain & 61 & 5458880 & 17.4 & 716054 & 20.5 & 4742826 & 17.0 & 74.3 & 54.7 & 1998-2014 \\
\hline Sweden & 80 & 1269620 & 4.0 & 258941 & 7.4 & 1010679 & 3.6 & 80.1 & 43.0 & 1998-2012 \\
\hline TOTAL & & 31407288 & 100 & 3485531 & 100 & 27921757 & 100 & 81.6 & 47.7 & \\
\hline
\end{tabular}

a Migrant Integration Policy Index for 2010.

0 (nulliparous) or 1 or more (multiparous). The 2010 MIPEX overall country score was used to indicate the level of policies conducive to migrants' integration in destination countries, on a scale from 0 to 100 (Migrant Integration Polic, 2018). We chose the overall MIPEX score for 2010 given the data reporting period. Furthermore the overall score based on eight policy areas was chosen over the MIPEX Health-specific score (based on only one policy area) as birthweight is likely to be influenced by a wider range of policies beyond the health sector. However, we performed sensitivity analyses with the MIPEX 2014 Health-specific score as well as the MIPEX overall scores for 2014.

\subsection{Statistical analyses}

Data were reported as the mean term birthweight estimate with standard deviation (SD) and number of observations within strata of the covariates. These estimates were then combined and analysed using regression techniques for aggregate data to obtain unadjusted and adjusted mean birthweight differences (Moineddin \& Urquia, 2014). Regression analysis of continuous aggregate data produces point estimates as well as $95 \%$ confidence intervals (CI), similar to those obtained using individual-level data (Moineddin \& Urquia, 2014). First, to assess the association between MIPEX score and birthweight across the ten destination countries, we calculated unadjusted and adjusted birthweight differences in grams associated with a 10-unit increase in MIPEX score for each maternal region of origin. Analyses were adjusted for year of birth, parity and maternal age group. We further modelled country of destination as a random intercept and calculated the proportion of country-level variance explained by the MIPEX. Second, to explore how the birthweight of different migrant groups relates to the birthweight of the native-born population, we plotted the birthweight difference between migrants and native-born on the $\mathrm{X}$-axis and the birthweight in native-born on the Y-axis, making one plot for each maternal region of origin. We added a horizontal line at the mean of the birthweight means of migrants from the specific world region. We also added a vertical line at the mean of the birthweight difference between migrants and the native-born. By doing this, we defined four quadrants (Q1-Q4) that classify destination countries. Q1: higher than average birthweight among native-born and migrants; Q2: lower than average birthweight among native-born and higher than average among migrants; Q3: higher than average birthweight among native-born and lower than average among migrants; and Q4: lower than average BW among native-born and migrants. We used the mean of the country means, as this gives equal weight to all destination countries irrespective of the number of births. Furthermore, to quantify variability in birthweight between destination countries we compared the birthweight of migrants of the same origin in different countries, using the country with the highest MIPEX score as the reference (Sweden), and adjusting for year of birth, parity and maternal age group. Analyses were performed in SAS (SAS Institute, Cary, NC) version 9.4.

\section{Results}

We included 31407288 births across the ten destination countries with complete information on maternal origin, age, parity and year of birth. The cohort is presented in Table 1. Maternal age was less than 35 years in $81.6 \%$ of all women, whilst $47.7 \%$ were nulliparous. The mean year of birth ranged from 2003 to 2007 in destination countries. Japan contributed the largest proportion of total births (46.7\%), followed by Spain (17.4\%) and Canada (14.9\%). Of all births, 3485531 births (11.1\%) were to migrant women. Canada (34.3\%), Spain $(20.5 \%)$ and Belgium (10.7\%) contributed the most births among migrant women. MIPEX overall scores for the year 2010 were available for all countries. Median score was 67; ranging from 42 for Japan to 80 for Sweden. Table 2 shows the distribution of maternal age groups, parity groups, median year of birth and mean birthweight in offspring to migrant and native-born women according to destination country. Table 3 shows the

Table 2

Maternal age, parity, year of birth and birthweight in migrants and native-born women according to destination countries.

\begin{tabular}{|c|c|c|c|c|c|c|c|c|c|}
\hline \multirow[t]{2}{*}{ Destination country } & \multirow[t]{2}{*}{ MIPEX $^{\mathrm{a}}$ score } & \multicolumn{2}{|c|}{ Maternal age $<35$ years (\%) } & \multicolumn{2}{|c|}{ Para $0(\%)$} & \multicolumn{2}{|c|}{ Year of birth (median) } & \multicolumn{2}{|c|}{ Birthweight in grams (Mean) } \\
\hline & & Migrants & Native-born & Migrants & Native-born & Migrants & Native-born & Migrants & Native-born \\
\hline Australia & 66 & 75.4 & 77.2 & 43.4 & 42.3 & 2008 & 2007 & 3386 & 3492 \\
\hline Belgium & 68 & 82.4 & 87.5 & 42.3 & 47.3 & 2005 & 2004 & 3317 & 3296 \\
\hline Canada & 71 & 75.6 & 85.4 & 41.7 & 44.7 & 2006 & 2005 & 3388 & 3506 \\
\hline Denmark & 49 & 82.5 & 82.8 & 37.5 & 42.1 & 2004 & 2004 & 3430 & 3532 \\
\hline Finland & 69 & 81.0 & 81.3 & 41.0 & 40.5 & 2009 & 2008 & 3509 & 3574 \\
\hline Japan & 42 & 81.8 & 83.9 & 48.3 & 48.5 & 2004 & 2004 & 3211 & 3067 \\
\hline Norway & 70 & 81.3 & 83.1 & 40.8 & 40.1 & 2008 & 2006 & 3484 & 3613 \\
\hline Scotland & 62 & 79.8 & 81.7 & 46.2 & 44.6 & 2009 & 2006 & 3439 & 3469 \\
\hline Spain & 61 & 83.1 & 72.9 & 53.3 & 54.9 & 2008 & 2006 & 3370 & 3278 \\
\hline Sweden & 80 & 79.3 & 80.3 & 39.0 & 44.0 & 2006 & 2005 & 3478 & 3610 \\
\hline ALL & & 79.2 & 81.9 & 44.6 & 48.1 & 2006 & 2005 & 3377 & 3241 \\
\hline
\end{tabular}

${ }^{\text {a }}$ Migrant Integration Policy Index for 2010. 


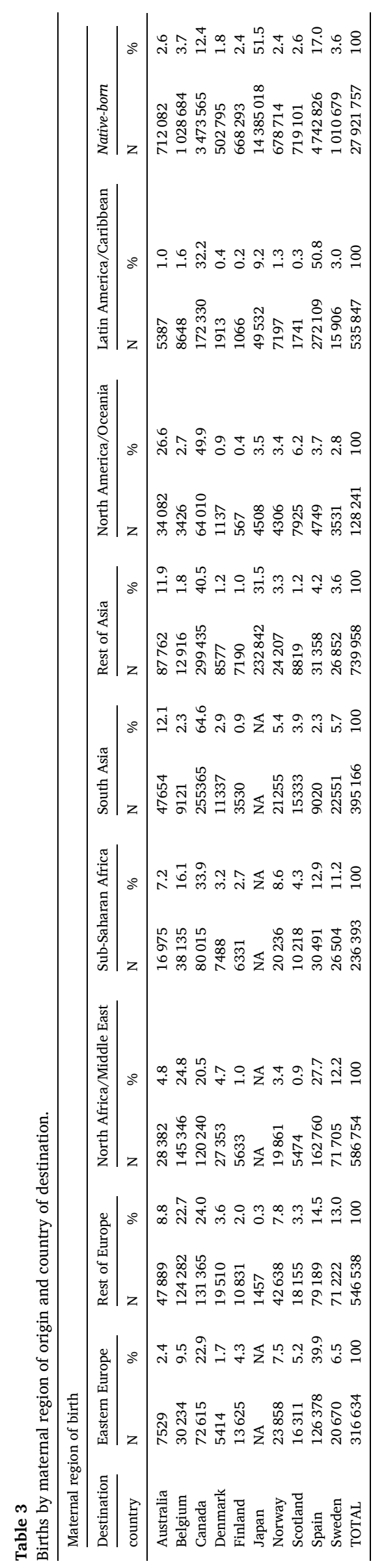

number and proportions of births in each maternal regional group for each destination country, which varied according to known migration patterns during the time period. Women born in the region Rest of Asia contributed the most births (21.1\%), followed by women born in North Africa/Middle East (16.8\%) and women born in the region Rest of Europe (15.7\%).

Table 4 shows the associations between MIPEX scores and birthweight across destination countries, by maternal region of birth, adjusted for year of birth, maternal age and parity groups. After including a random intercept for each destination country, we found a borderline association among women born in the rest of Asia, with an increase of $41 \mathrm{~g}$ (95\% CI: 2, 81), whereas among other groups no association was found. For native-born women, we found an association across the models, with an increase in birthweight of $105 \mathrm{~g}$ (95\% CI: 24, 186 ) with a 10-unit increase in MIPEX overall score. Variability of mean birthweight across destination countries was very small for all groups $(<2.5 \%)$.

Fig. 1 a-h shows for each maternal origin group, the absolute birthweight and crude birthweight differences compared to infants to women born in destination countries. With increasing birthweight among native-born women, the deficit in birthweight among migrant women became more pronounced. Overall, women from a given origin tended to have heavier babies in countries where the birthweight among the native-born was higher, and conversely have lighter babies in destination countries where the birthweight among the native-born was lower. North Africa/Middle East was the maternal geographic origin with the smallest variation in birthweight across destination countries among all migrant groups (70 g) (Fig. 1, c) and Latin America/Caribbean the one with the largest ( $285 \mathrm{~g}$ ) (Fig. 1, h). Mothers from South Asia all gave birth to lighter infants compared to native-born women, no matter where they gave birth (Fig. 1,e). In contrast, women from North America/Oceania mostly gave birth to heavier infants, compared to native-born women (Fig. 1, g). Nordic countries (Sweden, Finland, Norway and Denmark) were consistently in Q1 for all migrant groups, indicating a higher than average birthweight both among native-born and among migrants. Japan, Belgium and Spain were in Q4 for the majority of migrant groups, with birthweights lower than average among both among native-born and migrants. In seven out of eight migrant groups Scotland was located in Q2, thus had a lower than average birthweight among the native-born, but higher than average among migrants. Few countries had a higher than average birthweight among native-born and lower than average among migrants (Q3). Estimates for Canada and Australia were close to the average for both native-born and migrants for most regions. Exact estimates for mean birthweights with SD by maternal region of origin and by destination country are shown in Supplemental Table B. We also performed adjusted estimates for birthweight differences between migrants of the same origin in different destination countries; however, results did not change much compared to the unadjusted estimates (results not shown).

Supplementary Table $\mathrm{C}$ shows the top three countries as proportion of all births among migrants per region and per destination country. For Sub-Saharan Africa, the top three countries varied the most between destinations. For region Eastern Europe, North Africa, South Asia and North America, the top three were often the same countries, but in different order. We performed analyses with the MIPEX 2014 instead of the 2010 score; however, scores were highly correlated, and results were similar. We also applied the MIPEX Health-specific score 2014; however, the results did not change markedly (data not shown).

\section{Discussion}

Using multi-country data for more than 31 million births in ten OECD countries, we found that birthweight of babies born to migrant mothers from different regions of the world varies according to the country of destination. However, the MIPEX score, designed to measure favourable integration policies in destination countries, was not significantly 
Table 4

Association between MIPEX and birthweight across destination countries, by maternal region of birth.

\begin{tabular}{|c|c|c|c|c|}
\hline $\begin{array}{l}\text { Maternal region } \\
\text { of birth }\end{array}$ & $\begin{array}{l}\text { Mean birthweight difference (grams) associated } \\
\text { with 10-unit increase in MIPEX }(95 \% \mathrm{CI})^{\text {a }}\end{array}$ & $\begin{array}{l}\text { Mean birthweight difference (grams) associated } \\
\text { with 10-unit increase in MIPEX }\left(95 \% \text { CI) }{ }^{b}\right.\end{array}$ & $\begin{array}{l}\text { Destination country- } \\
\text { level variance } \%\end{array}$ & $\begin{array}{l}\text { Country-level variance } \\
\text { explained by MIPEX c } \%\end{array}$ \\
\hline Native-born & $144(139,148)$ & $105(24,186)$ & 0.2 & 34.4 \\
\hline Rest of Europe & $61(48,74)$ & $40(-15,95)$ & 0.3 & 20.6 \\
\hline East Europe & $78(69,88)$ & $25(-35,85)$ & 1.1 & -3.6 \\
\hline $\begin{array}{l}\text { North Africa/ } \\
\text { Middle East }\end{array}$ & $6(1,10)$ & $6(-18,29)$ & 0.1 & -10.4 \\
\hline $\begin{array}{l}\text { Sub-Saharan } \\
\text { Africa }\end{array}$ & $41(31,50)$ & $18(-38,74)$ & 0.8 & -7.1 \\
\hline Rest of Asia & $45(43,48)$ & $41(2,81)$ & 0.7 & 26.9 \\
\hline South Asia & $29(22,36)$ & $21(-38,81)$ & 0.9 & -6.6 \\
\hline $\begin{array}{l}\text { Latin America/ } \\
\text { Caribbean }\end{array}$ & $55(51,58)$ & $46(-1,93)$ & 1.1 & 23.7 \\
\hline $\begin{array}{l}\text { North America/ } \\
\text { Oceania }\end{array}$ & $33(25,40)$ & $40(-8,86)$ & 2.2 & 16.3 \\
\hline
\end{tabular}

MIPEX $=$ Migrant Integration Policy Index. $\mathrm{CI}=$ confidence interval.

a Adjusted for year of birth, parity and maternal age group.

b Same as (1) and including a random intercept for each destination country.

c The country-level variance explained by MIPEX is the $\%$ of the explainable variance in the adjacent column. Therefore, $34 \%$ of $0.2 \%$ means that the MIPEX explains a substantial part of very little.

associated with birthweight among most migrant groups. Interestingly, the MIPEX score was associated with birthweight among non-migrants, suggesting that the index may capture broader characteristics of the local policy and social environment and may not necessarily be migrantspecific. A clearer pattern emerged when comparing migrants' birthweight with that of non-migrants. For all eight regional groups of migrants, offspring mean birthweight was highest in the Nordic countries, with Finland and Sweden at the top. Birthweight was lowest in Japan, followed by Belgium and Spain. Thus, women from a given origin tended to have heavier newborns in countries where the mean birthweight among those of the native-born women was higher, and have lighter newborns in destination countries where the mean birthweight among the native-born was lower. These findings suggests that unmeasured environmental characteristics of the destination countries may be "pulling" migrants' birthweight towards the level experienced by their non-migrant counterparts.

\subsection{Strengths and limitations}

The strength of this study is the use of a large multi-country population-based data set from ten countries, including more than three million births among migrant women and 27 million births among native-born women. We were able to use individual-level data, but at a high level of aggregation. Birthweight is measured with high accuracy and reliability. Maternal regional origin and covariates were standardised across participating countries.

There are several limitations to this study. We could not include covariates such as maternal body mass index (BMI), maternal smoking, mode of birth, father's region of origin, refugee status or duration of residence, due to absence of such information in many participating countries or small cell size disclosure restrictions. Furthermore, in this study we classified migrant women according to their region of origin, disregarding the heterogeneity within such large geographical units (see Supplementary Table C). In addition, migration patterns are shaped by historical events and may have differed in time and place for each destination country.

\subsection{Interpretation}

To our knowledge, this is the first multi-country population-based study assessing term birthweight differences between destination countries for migrants originating in different world regions.

Our main discovery, comparing birthweight in the native-born population to different migrant groups across destination countries, was that migrants' birthweights were higher in countries with high birthweights in the local population and lower in countries with lower birthweights in the local population. This was a consistent magnet-effect where the birthweight among native-born seems to "pull" the birthweight of migrant groups, no matter in which world region the mother was born. This pattern may partially reflect migrant integration policies, but also other unmeasured features of the social and policy environment of the destination countries. However, such an effect might not be confirmed in countries where selective migration and health care influences are less of an issue (Juarez \& Hjern, 2017). Further investigation is needed as to which specific policy elements that protect societal/financial benefits for women also promote health and well-being.

We did not find a consistent association between the MIPEX score and mean term birthweight. All the Nordic countries came out on top in terms of birthweight in every regional migrant group. Nordic countries have traditionally had similar state welfare policies and women-friendly policies. However, Denmark's MIPEX scores were considerably lower; yet the country produces birthweights among migrants almost as high as those observed in other Nordic countries. Similarly, migrants in Belgium produced disproportionately low birthweights for a MIPEX score near the average. This finding is not entirely paradoxical given that some countries have high-quality maternity care systems even if they have poor or average integration policies.

Contrary to previous reports that have shown MIPEX to be useful in predicting migrant health outcomes such as self-reported health and long-standing illness (Giannoni, Franzini, \& Masiero, 2016; Malmusi, 2015) this is not the case for birthweight. In addition to differential selection of migrants to countries, another potential explanation for the poor predictive ability of MIPEX is that the score exhibited insufficient variability between our included countries to be able to detect an association with the complex health outcome of birthweight. The fact that the MIPEX score predicted mean birthweight in the native population warrants further studies to explore if the base indicators grasp central societal aspects of the destination country that are associated with generally progressive social and economic policies (Migrant Integration Polic, 2018).

Our purpose was to explore birthweight differences as a measure of population health and not as a clinically relevant end-point or in terms of optimal birthweights. However, the mean absolute difference in offspring birthweight for women from the same geographic region of origin across the ten destination countries was around $200 \mathrm{~g}$. This magnitude is comparable to that of maternal smoking, high BMI or gestational weight gain (Juarez \& Merlo, 2013). The mean absolute 
(a) Mothers from Eastern Europe

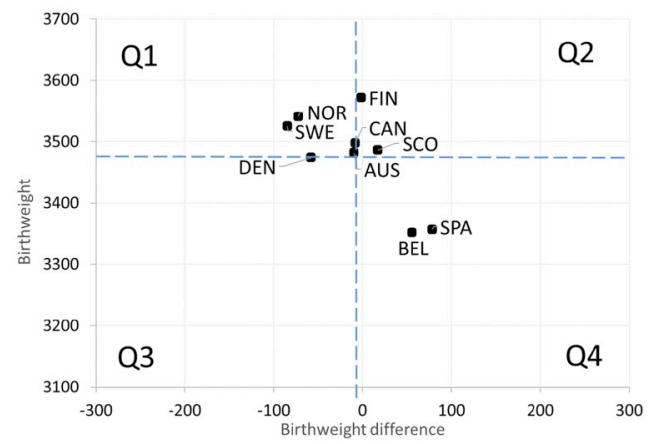

(c) Mothers from North Africa and Middle East

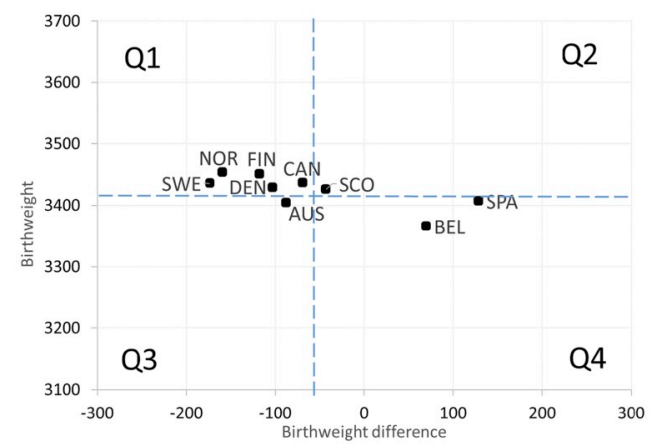

(e) Mothers from South Asia

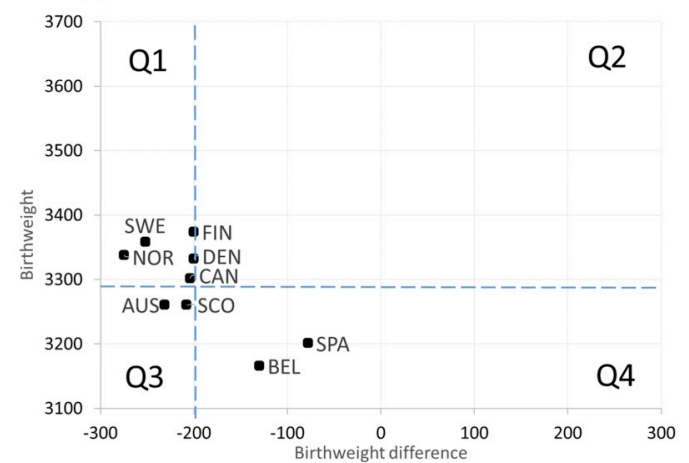

(g) Mothers from North America and Oceania

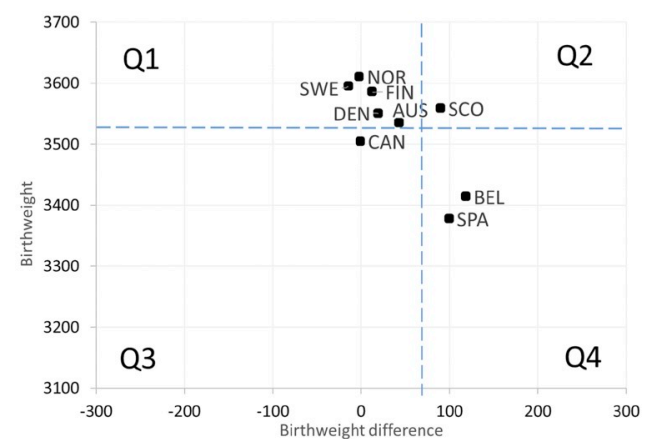

(b) Mothers from Rest of Europe

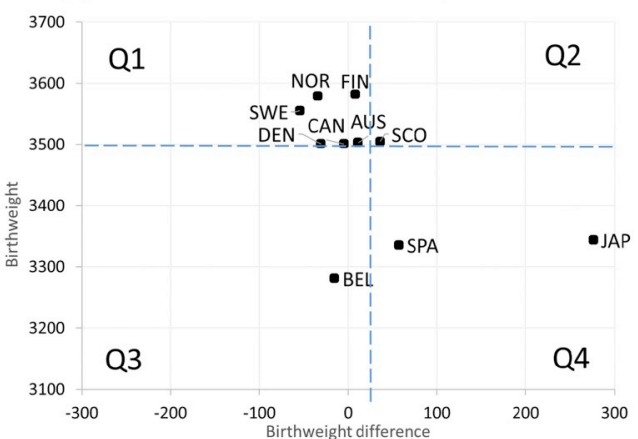

(d) Mothers from Subsaharan Africa

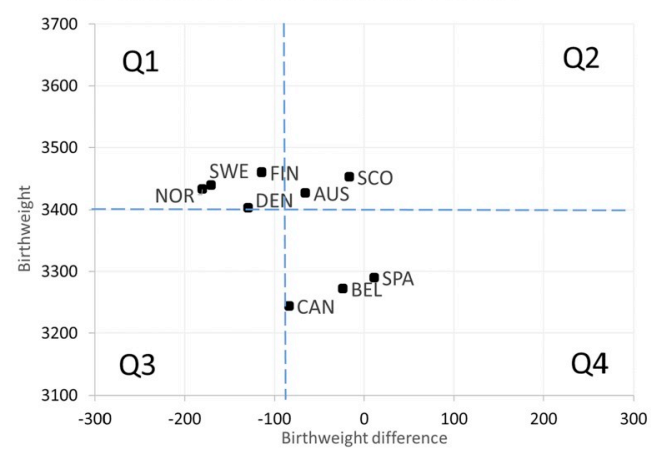

(f) Mothers from Rest of Asia

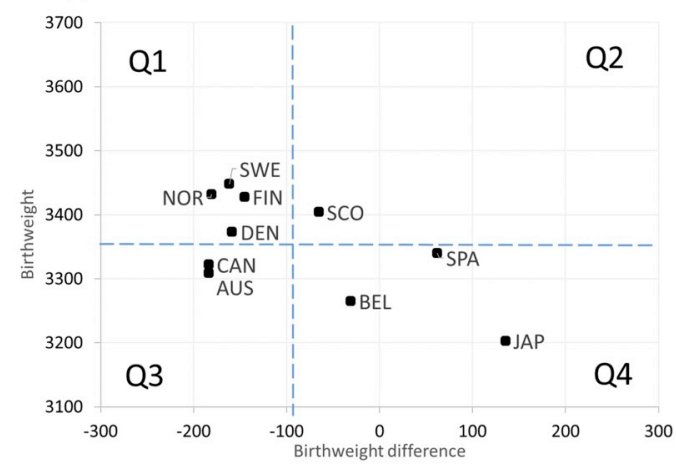

(h) Mothers from Latin America and Caribbean

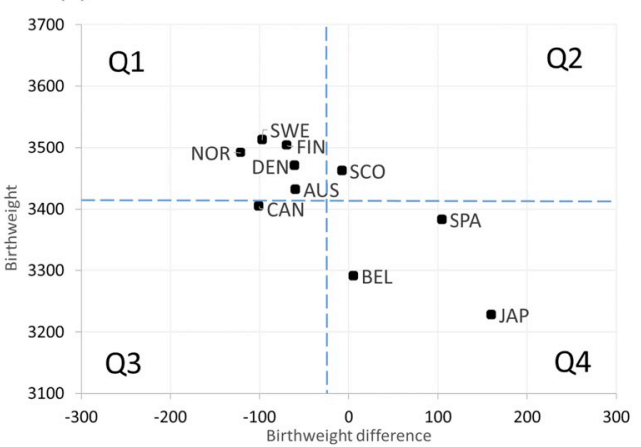

Dashed blue horizontal line: Mean of the birthweight (BW) means of migrants across destination countries.

Dashed blue vertical line: Mean of the mean BW differences between migrants and the native-born across destination countries. Countries in Q1 are those with both higher than average BW among native-born and migrants. Countries in Q2 are those with lower than average BW among native-born and higher than average among migrants. Countries in Q3 are those with higher than average BW among native-born and lower than average among migrants. Countries in Q4 are those with both lower than average BW among native-born and migrants.

Fig. 1. (a-h) Birthweight differences in migrants compared to native-born by destination country and according to maternal origin. 
difference in offspring birthweight across the ten destination countries varied by maternal region of origin, from $285 \mathrm{~g}$ for women from Latin America/Caribbean to $70 \mathrm{~g}$ among women from North Africa/Middle East. The resulting mean birthweight differences in our study are likely to be a minimum estimate, and the real differences could be higher if migrant groups were further disaggregated. Our findings differ somewhat from the findings of a binational study showing that Spanish-speaking Latin American migrants in Canada had newborns $100 \mathrm{~g}$ heavier than their same-country counterparts giving birth in Spain (Urquia et al., 2015). This difference is likely due to pooling Latin Americans/Caribbean as a single group in our study. Caribbeans are more common in some countries (e.g., Canada) but not in others (Nordic countries). As Caribbean-born women are known to have poorer pregnancy outcomes, such as preterm birth, they are expected to lower the mean in the destination countries where they are more prevalent (Park, Urquia, \& Ray, 2015). The strikingly low variability of birthweight among the North African/Middle East group points to homogeneity in this group. Migrants to Japan had the lowest offspring birthweight compared to migrants of the same origin arriving in any other destination country, which could be related to the low levels of obesity and gestational weight gain in the native-born population (Morisaki, Kawachi, Oken, \& Fujiwara, 2016).

If selective migration was the driving factor we would expect the highest birthweights in Australia and Canada, countries that limit the number of humanitarian admissions in favour of migrants who can contribute to the economy. However, countries with the highest birthweights in our study, the Nordic countries, do not have specific admission policies and accept a fair proportion of refugees and asylum seekers. Thus, our results are not likely to be primarily driven by countries "skimming the cream" in regards to picking the socioeconomically welloff migrants. Although Denmark was an outlier in terms of having a low MIPEX, but producing high birthweights, we did not find any indication that our findings were heavily influenced by selective migration of healthier women to richer countries. At the lower end of the birthweight scale, Spain has a high proportion of illegal migrants, who might be vulnerable with regards to access to pregnancy care and unstable living conditions. Belgium also has a disproportionately high proportion of asylum seekers in relation to other EU countries, and a high proportion of undocumented migrants (Indicators of Immig, 2015, pp. 37-51). All in all, the pattern of the birthweight of migrants being pulled to that of the native-born population is not consistent with selective migration as the major explanation.

\section{Conclusion}

Using multi-country data for more than 31 million births in ten OECD countries, the MIPEX score does not explain the variations seen in birthweight of migrants across destination countries. However, migrant women from a given origin tended to have heavier babies in countries where birthweight of the native-born was higher, and vice versa. We need further investigation into which broader social policies as well as specific components of maternity care support women and have impact on perinatal outcomes like birthweight.

\section{Contribution to authorship}

IS, MU and SV conceived the study. IS and MU analysed the data and led the writing process. FB, NM, MG, SJ, AMNA, JR, RS, RW, MU and IS contributed data and results for analysis. All authors contributed to the study design, writing of the manuscript and approved the final version.

\section{Funding}

The study was partially funded by a post-doctoral fellowship from the Norwegian National Advisory Board on Women's Health, Oslo University Hospital HF, Norway. Analysis regarding data from Japan was supported by a grant from the Ministry of Health, Labour and Welfare, Tokyo, Japan (H28-ICT-ippan-001). MLU is supported by a Canada Research Chair in Applied Population Health. All authors were supported by their respective institutions. The funding sources had no role in study design, in collection, analysis and interpretation of data or in the writing of the report. All authors had full access to study results and had final responsibility for the decision to submit for publication.

\section{Declaration of competing interest}

None.

\section{Acknowledgements}

We would like to thank the Reproductive Outcomes And Migration (ROAM) collaborative research network for support throughout this process, especially the head of the Steering Committee Professor Birgitta Essén at the Department of Women's and Children's Health, University of Uppsala, Sweden, and Professor Alison Macfarlane, City University of London, United Kingdom, for valuable input. We thank Professor Anders Hjern at Karolinska Institute, Sweden, for access to the Swedish data and statistician Adela Castello at the Unit of Public Health, University of Alcalá, Spain, for assisting in analysis of the Spanish results.

\section{Appendix A. Supplementary data}

Supplementary data to this article can be found online at https://doi. org/10.1016/j.ssmph.2019.100503.

\section{References}

Bollini, P., Pampallona, S., Wanner, P., \& Kupelnick, B. (2009). Pregnancy outcome of migrant women and integration policy: A systematic review of the international literature. Social Science \& Medicine, 68(3), 452-461.

Delnord, M., Hindori-Mohangoo, A. D., Smith, L. K., Szamotulska, K., Richards, J., DebRinker, P., et al. (2017 Apr). Variations in very preterm birth rates in 30 high-income countries: Are valid international comparisons possible using routine data? BJOG, 124(5), 785-794. https://doi.org/10.1111/1471-0528.14273.

Gagnon, A., Zimbeck, M., Zeitlin, J., ROAM Collaboration, Alexander, S., Blondel, B., et al. (2009). Migration to western industrialised countries and perinatal health: A systematic review. Social Science \& Medicine, 69(6), 934-946.

Gardosi, J., Francis, A., Turner, S., \& Williams, M. (2018). Customized growth charts: Rationale, validation and clinical benefits. American Journal of Obstetrics and Gynecology, 218(2S), S609-S618.

Giannoni, M., Franzini, L., \& Masiero, G. (2016). Migrant integration policies and health inequalities in Europe. BMC Public Health, 16, 463.

Gissler, M., Alexander, S., Macfarlane, A., Small, R., Stray-Pedersen, B., Zeitlin, J., et al. (2009). Stillbirths and infant deaths among migrants in industrialized countries. Acta Obstetricia et Gynecologica Scandinavica, 88(2), 134-148.

Goel, M. S., McCarthy, E. P., Phillips, R. S., \& Wee, C. C. (2004). Obesity among US immigrant subgroups by duration of residence. Journal of the American Medical Association, 292(23), 2860-2867.

Hawkins, S. S., Lamb, K., Cole, T. J., \& Law, C. (2008). Influence of moving to the UK on maternal health behaviours: Prospective cohort study. BMJ, 336(7652), 1052-1055.

Joseph, K. S., Liu, S., Rouleau, J., Lisonkova, S., Hutcheon, J. A., Sauve, R., et al. (2012). Influence of definition based versus pragmatic birth registration on international comparisons of perinatal and infant mortality: Population based retrospective study. $B M J, 344$, e746.

Juarez, S. P., \& Hjern, A. (2017). The weight of inequalities: Duration of residence and offspring's birthweight among migrant mothers in Sweden. Social Science \& Medicine, 175, 81-90.

Juarez, S. P., Honkaniemi, H., Dunlavy, A. C., Aldridge, R. W., Barreto, M. L., Katikireddi, S. V., et al. (2019). Effects of non-health-targeted policies on migrant health: A systematic review and meta-analysis. Lancet Glob Health, 7(4), e420-e435.

Juarez, S. P., \& Merlo, J. (2013). Revisiting the effect of maternal smoking during pregnancy on offspring birthweight: A quasi-experimental sibling analysis in Sweden. PLoS ONE [Electronic Resource], 8(4), e61734.

Kana, M. A., Correia, S., Peleteiro, B., Severo, M., \& Barros, H. (2017). Impact of the global financial crisis on low birth weight in Portugal: A time-trend analysis. BMJ Glob Health, 2(2), e000147.

Malmusi, D. (2015). Immigrants' health and health inequality by type of integration policies in European countries. The European Journal of Public Health, 25(2), 293-299.

Migrant integration policy index accessed 10.12.18 2018 www.mipex.eu.

Moineddin, R., \& Urquia, M. L. (2014). Regression analysis of aggregate continuous data. Epidemiology, 25(6), 929-930. 
Morisaki, N., Kawachi, I., Oken, E., \& Fujiwara, T. (2016). Parental characteristics can explain why Japanese women give birth to the smallest infants in the United States. Paediatric \& Perinatal Epidemiology, 30(5), 473-478.

Novak, N. L., Geronimus, A. T., \& Martinez-Cardoso, A. M. (2017). Change in birth outcomes among infants born to Latina mothers after a major immigration raid. International Journal of Epidemiology, 46(3), 839-849.

OECD. Indicators of immigrant integration 2015: Settling in. 02.07.15 ed. Paris, France (pp. 37-51). (2015). Paris: OECD Publishing.

Oza-Frank, R., Stephenson, R., \& Narayan, K. M. (2011). Diabetes prevalence by length of residence among US immigrants. JImmigrMinorHealth, 13(1), 1-8.

Park, A. L., Urquia, M. L., \& Ray, J. G. (2015). Risk of preterm birth according to maternal and paternal country of birth: A population-based study. Journal of Obstetrics and Gynaecology Canada, 37(12), 1053-1062.

Ray, J. G., Sgro, M., Mamdani, M. M., Glazier, R. H., Bocking, A., Hilluard, R., et al. (2012). Birth weight curves tailored to maternal world region. Journal of Obstetrics and Gynaecology Canada, 34(2), 159-171.

Reproductive outcomes and migration network accessed 10.12.18 2018 https://www. roamscicoll.org/.

Seaton, S. E., Yadav, K. D., Field, D. J., Khunti, K., \& Manktelow, B. N. (2011). Birthweight centile charts for South Asian infants born in the UK. Neonatology, 100 (4), 398-403.

United Nations geographic regions accessed 10.10.16 2016 https://unstats.un.org/uns d/methodology/m49/.
Urquia, M. L., Sørbye, I. K., \& Wanigaratne, S. (2016). Birth-weight charts and immigrant populations: A critical review. Best Practice \& Research Clinical Obstetrics \& Gynaecology, 32, 69-76.

Urquia, M. L., Vang, Z. M., \& Bolumar, F. (2015). Birth outcomes of Latin Americans in two countries with contrasting immigration admission policies: Canada and Spain. PLoS One, 10(8), e0136308.

Vangen, S., Stoltenberg, C., Skjaerven, R., Magnus, P., Harris, J. R., \& Stray-Pedersen, B. (2002). The heavier the better? Birthweight and perinatal mortality in different ethnic groups. International Journal of Epidemiology, 31(3), 654-660.

Villar, J., Papageorghiou, A. T., Pang, R., Ohuma, E. O., Cheikh Ismail, L., Barros, F. C., et al. (2014). The likeness of fetal growth and newborn size across non-isolated populations in the INTERGROWTH-21st project: The fetal growth longitudinal study and newborn cross-sectional study. Lancet Diabetes Endocrinol, 2(10), 781-792.

Wehby, G. L., Gili, J. A., Pawluk, M., Castilla, E. E., \& Lopez-Camelo, J. S. (2015). Disparities in birth weight and gestational age by ethnic ancestry in South American countries. International Journal of Public Health, 60(3), 343-351.

Weightman, A. L., Morgan, H. E., Shepherd, M. A., Kitcher, H., Roberts, C., \& Dunstan, F. D. (2012). Social inequality and infant health in the UK: Systematic review and meta-analyses. BMJ Open, 2(3).

Wilcox, A. J. (2001). On the importance-and the unimportance-of birthweight. International Journal of Epidemiology, 30(6), 1233-1241. 